See Article page e109.

\section{Commentary: Ex vivo lung perfusion plus solute adsorption: An exorcism of evil humors?}

\author{
Ian C. Glenn, MD, and Siva Raja, MD, PhD
}

Ex vivo lung perfusion (EVLP) allows for the normothermic assessment of lung graft function and provides a potential opportunity to "rehabilitate" lungs following procurement. ${ }^{1,2}$ This has allowed for the expansion of the pool of potential donors to include more high-risk individuals. Given the significant discordance in numbers between those in need of transplantation and available organs, there is significant research dedicated to reducing this disparity. In its current state, EVLP is far from being able to eliminate the imbalance between supply and demand for lungs. ${ }^{3}$

The work of Iskender and colleagues ${ }^{4}$ has the potential to contribute to the advancement of EVLP and increase the number of lung transplantations by adding a solute adsorption system to the EVLP circuit. Their animal model studied porcine donor lungs that had been preserved for 24 hours, followed by 6 hours of EVLP in accordance with the Toronto protocol. The lungs were split into a treatment group and a control group, with the treatment group EVLP circuit using the proprietary CytoSorb adsorber (CytoSorbent, Monmouth Junction, NJ), the stated purpose of which is to adsorb circulating cytokines, given that proinflammatory cytokines have been associated with primary graft dysfunction. ${ }^{5}$ The lungs were then transplanted, and the porcine recipients were then observed for 4 hours, with measurement of physiological and biochemical function.

The EVLP plus CytoSorb system was associated with lower concentrations of acute-phase reactants and proinflammatory cytokines. The CytoSorb system was also seen to remove other molecules, such as antibiotics and steroids. Of more clinical relevance, the grafts in the treatment

\footnotetext{
From the Department of Thoracic and Cardiovascular Surgery, Heart and Vascular Institute, Cleveland Clinic, Cleveland, Ohio.

Disclosures: Authors have nothing to disclose with regard to commercial support.

Received for publication Dec 3, 2019; accepted for publication Dec 3, 2019; available ahead of print Dec 21, 2020.

Address for reprints: Siva Raja, MD, PhD, Heart and Vascular Institute, Cleveland Clinic, 9500 Euclid Ave, J4-1, Cleveland, OH 44195 (E-mail: rajas@ccf.org).

J Thorac Cardiovasc Surg 2021;161:e123-4 0022-5223/\$36.00

Copyright (c) 2019 Published by Elsevier Inc. on behalf of The American Association for Thoracic Surgery

https://doi.org/10.1016/j.jtcvs.2019.12.009
}

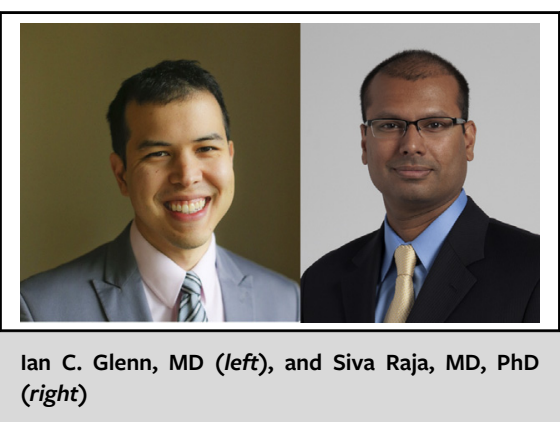

CENTRAL MESSAGE

Ex vivo perfusion with an adsorption membrane improves short-term graft function in a porcine model. Although this finding is provocative, its true value needs to be vetted in the real world.

group had more favorable physiological parameters, such as lung mechanics and gas exchange.

In this highly controlled system, the authors demonstrate the value of the adsorption membrane. Unfortunately, however, life is not always a controlled environment, and patients undergoing lung transplantation have a much more complex immunologic/inflammatory milieu. The membrane appears to be nonselective in removing both proinflammatory and antiinflammatory molecules among other things, such as medications. As such, the value in real-life scenarios will be rather unpredictable. However, modern medicine got things right before knowing why they got it right. Modern concepts of infection control started as way to exorcise "evil humors" before a strong grasp of microbiology. Nevertheless, it can be a good start. The question is whether this system is merely one small step in the right direction or a giant leap for lung transplantation.

Overall, the findings by Iskender and colleagues are promising, but it is a bit too early to determine the long-term significance of this research. At a minimum, this work should prompt future investigations into ways to increase the pool of organs available for transplantation. Ultimately, this new technology needs to be demonstrated in human studies before it can be determined whether this will usher in a new age for EVLP and lung transplantation or we will have to wait for the next disruptive technology, such as bioengineered lungs, for such a breakthrough. 


\section{References}

1. Cypel M, Yeung JC, Liu M, Anraku M, Chen F, Karolak W, et al. Normothermic ex vivo lung perfusion in clinical lung transplantation. $N$ Engl J Med. 2011;364: 1431-40.

2. Machuca TN, Cypel M. Ex vivo lung perfusion. J Thorac Dis. 2014;6: 1054-62.

3. Boffini M, Ricci D, Barbero C, Bonato R, Ribezzo M, Mancuso E, et al. Ex vivo lung perfusion increases the pool of lung grafts: analysis of its po- tential and real impact on a lung transplant program. Transplant Proc 2013;45:2624-6.

4. Iskender I, Arni S, Maeyashiki T, Citak N, Sauer M, Caviezel A, et al. Perfusate adsorption during ex vivo lung perfusion improves early post-transplant lung function. J Thorac Cardiovasc Surg. 2021;161:e109-21.

5. Machuca TN, Cypel M, Yeung JC, Bonato R, Zamel R, Chen M, et al. Protein expression profiling predicts graft performance in clinical ex vivo lung perfusion. Ann Surg. 2015;261:591-7.
See Article page e109.

\section{Commentary: Ischemia reperfusion-Looking ahead}

\author{
Eugene Golts, MD, and Mark Onaitis, MD
}

The number of lung transplantations has increased steadily over the past 2 decades. The experience gained over this time period has allowed physicians to accept higher-risk patients for transplantation and to expand the donor pool regarding both the quality of the organs and the ischemic time associated with travel for procurement. Travel times will most likely continue to increase if the hard borders for lung allocation are removed, as has been proposed recently. ${ }^{1}$

The cost of longer ischemic time is the development of more severe ischemia-reperfusion (IR) injury. IR injury has been defined as acute sterile inflammation after ischemic insult to the donor lungs and reestablishment of pulmonary blood flow in the recipient body. ${ }^{2}$

Clinical strategies to ameliorate the effects of IR injury are limited and focused on shortening the duration of ischemia, as well as on performing controlled reperfusion of the lungs. More recently, experimental approaches including the removal of free radicals and addition of anti-inflammatory substances have been described.

An extension of these approaches is described by Iskender and colleagues ${ }^{3}$ in this issue of the Journal, demonstrating that perfusate adsorption during ex vivo lung perfusion

\footnotetext{
From the Division of Cardiothoracic Surgery, Department of Surgery, University of California San Diego, La Jolla, Calif.

Disclosures: Authors have nothing to disclose with regard to commercial support.

Received for publication Dec 10, 2019; accepted for publication Dec 10, 2019; available ahead of print Dec 20, 2020

Address for reprints: Mark Onaitis, MD, 9300 Campus Point Drive, 7892, La Jolla, CA 92037 (E-mail: monaitis@ health.ucsd.edu).

J Thorac Cardiovasc Surg 2021;161:e124-5 0022-5223/ $\$ 36.00$

Copyright $₫ 2020$ Published by Elsevier Inc. on behalf of The American Association for Thoracic Surgery

https://doi.org/10.1016/j.jtcvs.2019.12.010
}

Check for updates

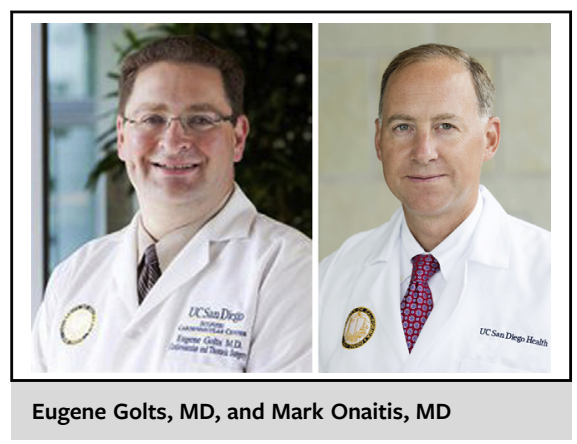

CENTRAL MESSAGE

Optimizing lung transplant organ

outcomes via absorption of in-

flammatory mediators causing

ischemia-reperfusion injury is an

exciting possibility.

ameliorates the effects of IR injury to porcine allografts. The authors report this method to be largely effective, as demonstrated by a significant decrease in the concentration of interleukin (IL)-1ra in the plasma of transplanted animals after reperfusion, as well as statistically significant decreases in the concentrations of IL-1ra, IL-6, and IL-8 in the bronchial wash fluid at 4 hours after lung implantation.

Furthermore, the authors demonstrate significantly higher dynamic compliance in the transplanted lungs, accompanied by improvement of gas exchange in the treated lungs that closely approaches the threshold of statistical significance. Although these findings are very impressive and potentially clinically useful, a histological analysis of transplanted lungs performed by 2 independent pathologists failed to demonstrate a decrease in the level of neutrophil recruitment into the lungs or of vascular endothelial cellular activation in the treatment group compared with controls. 